\title{
ANALISIS FINANSIAL USAHA PEMBIBITAN LAMPOH BIJEH DI KOTA LANGSA
}

\author{
Supristiwendi ${ }^{1} /$ Yulita Safni ${ }^{2}$ \\ ${ }^{1}$ Dosen Tetap Prodi Agribinis \\ ${ }^{2}$ Alumni Prodi Agribinisnis \\ Fakultas Pertanian Universitas Samudra
}

\section{RINGKASAN}

Penelitian ini adalah studi kasus di Usaha Pembibitan "Lampoh Bijeh" yang terletak di Kecamatan Langsa Baro Kota Langsa. Tujuan penelitian untuk mengetahui kelayakan usaha pembibitan tanaman Lampoh Bijeh di Kota Langsa dari segi finansial.

Penelitian merupakan studi kasus pada usaha pembibitan Lampoh Bijeh Kota Langsa. Objek dalam penelitian ini hanya dibatasi pada usaha pembibitan tanaman Lampoh Bijeh di Kota Langsa. Ruang lingkup penelitian ini meliputi analisis finansial yang meliputi NPV, IRR, Net B/C dan PBP usaha pembibitan tanaman Lampoh Bijeh di Kota Langsa.

Hasil analisis finansial untuk 4 (empat) penilaian kriteria investasi semuanya layak. Nilai NPV sebesar Rp. 46.843.766,53 adalah lebih besar dari 0 maka dari sisi NPV usaha pembibitan tanaman Lampoh Bijeh layak untuk dikerjakan. Nilai IRR sebesar 12,4\% lebih besar dari bunga pinjaman bank berlaku yaitu $12 \%$, maka dari sisi IRR usaha pembibitan tanaman Lampoh Bijeh layak untuk dikerjakan. Nilai Net B/C sebesar 1,77 adalah lebih besar dari 1, maka dari sisi Net B/C usaha pembibitan tanaman Lampoh Bijeh layak untuk dikerjakan. Nilai PBP sebesar 3,42 tahun adalah lebih kecil dari umur proyek yaitu 5 tahun, maka dari sisi PBP usaha pembibitan tanaman Lampoh Bijeh layak untuk dikerjakan.

Kata Kunci: Bibit, Biaya Produksi, Penerimaan, Pendapatan, Analisis Finansial,

\section{PENDAHULUAN \\ Latar Belakang}

Sektor pertanian masih memegang peranan penting dalam pembangunan ekonomi nasional. Karena Indonesia tergolong kedalam Negara sedang berkembang dan pertanian memberikan kontribusi yang besar bagi pembangunan ekonomi Indonesia.

Hal ini sesuai dengan yang dikemukakan oleh Widodo (2008:1) yaitu "pertanian memberikan kontribusi yang besar bagi pembangunan ekonomi sebagai kontribusi produksi, kontribusi pasar, kontribusi faktor produksi dan kontribusi devisa". Besarnya kontribusi yang disumbang sektor pertanian begitu saja dari perekonomian nasional, tapi justru sebaliknya sektor pertanian akan diberikan perhatian yang besar oleh pemerintah dengan menerapkan berbagai kebijakan, baik kebijakan dibidang produksi, pemasaran, begitu juga dengan bidang-bidang lainnya.

Pembibitan merupakan usaha untuk memperbanyak tanaman baik secara generatif (biji) maupun secara vegetatif (stek, cangkok, okulasi, sambung) agar memperoleh bahan tanaman yang baru menggantikan tanaman yang tua atau rusak.
Pembibitan tanaman merupakan salah satu usaha di sektor pertanian yang bergerak di bidang produksi sampai kepada pemasaran bibit tanaman. Pentingnya bibit dalam usaha pertanian sudah tidak diragukan lagi. Bagi Negara-negara yang industri pembibitannya maju, mereka dapat menghasilkan produkproduk pertanian yang bermutu tinggi dan berdaya saing tinggi. Hal ini berkaitan erat dengan penguasaan teknologi pemuliaan serta pengawasan mutu bibit dan bibit yang baik (Winarno, 1990: 15).

Usaha pembibitan harus didasarkan dengan memproduksi bibit tanaman yang mempunyai kualitas baik, agar apabila ditanam di lapangan secara luas akan mengahasilkan produksi yang baik pula. Pengawasan mutu bibit dan bibit yang baik diperlukan dalam suatu usahatani agar kegiatan usahatani terlaksana dengan baik. Bibit merupakan salah satu penentu keberhasilan budidaya tanaman. Budidaya tanaman dimulai sejak memilih bibit tanaman yang baik. Hal ini dikarenakan bibit merupakan obyek utama yang akan dikembangkan dalam proses budidaya selanjutnya. Dengan demikian, untuk memperoleh tanaman yang memiliki sifat tertentu, dapat diperoleh dengan memilih bibit 
yang memiliki sifat seperti yang diinginkan, misalnya untuk mendapat tanaman mangga yang memiliki sifat buah besar dan manis, maka hanya dapat diperoleh dengan menanam bibit varietas umggul (Nusmawarhaeni, 2001: 75).

Usaha penangkaran bibit Lampoh Bijeh di Kota Langsa Desa Paya Bujok Seuleumak Kecamatan Langsa Baro adalah salah satu penangkaran bibit yang ada di Kota

Tabel I-1. Perkembangan Produksi Usaha Pembibitan Lampoh Bijeh Perjenis Bibit Pada Tahun 2011 2015

\begin{tabular}{|c|c|c|c|c|c|c|c|}
\hline \multirow[b]{2}{*}{ No } & \multirow[b]{2}{*}{ Jenis Bibit } & \multicolumn{5}{|c|}{ Tahun } & \multirow[b]{2}{*}{ Total } \\
\hline & & 2011 & 2012 & 2013 & 2014 & 2015 & \\
\hline 1 & Mangga & 500 & 1000 & 1200 & 1200 & 1000 & 4900 \\
\hline 2 & Mahoni & 1000 & 500 & 1000 & 1000 & 1500 & 5000 \\
\hline 3 & Jambu Jamaica & 200 & 200 & 200 & 200 & 200 & 1000 \\
\hline 4 & Rambutan & 500 & 500 & 500 & 500 & 500 & 2500 \\
\hline 5 & Jabon & 1000 & 1000 & 1200 & 1500 & 1500 & 6200 \\
\hline 6 & Jati & 1000 & 1000 & 1000 & 1500 & 1700 & 6200 \\
\hline 7 & Asam Jawa & 200 & 200 & 200 & 200 & 200 & 1000 \\
\hline 8 & Asam Glugur & 200 & 200 & 200 & 200 & 200 & 1000 \\
\hline 9 & Jeruk Purut & 200 & 200 & 200 & 200 & 200 & 1000 \\
\hline 10 & Kelapa Sawit & 1000 & 1500 & 1500 & 2000 & 2000 & 8000 \\
\hline 11 & Kakao & 1000 & 1000 & 1000 & 800 & 1000 & 4800 \\
\hline 12 & Belimbing & 200 & 200 & 200 & 200 & 200 & 1000 \\
\hline 13 & Karet & 1000 & 500 & 0 & 0 & 0 & 1500 \\
\hline
\end{tabular}

Sumber: Usaha Lampoh Bijeh, 2016

Tabel I-1 menjelaskan bahwa terjadi perkembangan yang stabil produksi bibit di usaha pembibitan Lampoh Bijeh perjenis bibit.

Keberhasilan penanaman tanaman buah dan hutan sangat ditentukan oleh mutu benih dan mutu bibit yang digunakan. Mutu benih ditentukan oleh sifat genetik dan pengolahannya, sedangkan mutu bibit selain ditentukan oleh mutu benih juga ditentukan teknik pengolahannya selama persemaian. Didalam menyiapkan agar sumber benih menghasilkan benih bermutu dengan junlah banyak, maka semua itu harus dikelola dengan baik. Pengelolaan meliputi pemeliharaan tanaman, penyediaan benih dan sampai penyalurannya. Pengelolaan pembibitan sangat perlu dilakukan karena merupakan langkah awal untuk menyiapkan bahan tanam yang sehat dan bermutu dan didalam pelaksanaanya, pembibitan harus betul-betul dilaksanakan sesuai teknis dan mengikuti aturan yang telah ditentukan.
Langsa yang mengusahakan beberapa jenis komoditi bibit tanaman pertanian yaitu seperti mangga dan jambu air. Melihat prospek penangkaran bibit Lampoh Bijeh dimasa mendatang yang masih terbuka peluang untuk meningkatkan pengembangan kegiatan. Perkembangan produksi usaha pembibitan Lampoh Bijeh dari tahun 2011 sampai 2015 dapat dilihat pada tabel berikut.
Analisis finansial merupakan bahan pertimbangan layak atau tidak pelaksanaan suatu usaha. Pengertian layak dalam penilaian ini adalah manfaat (benefit) yang diperoleh dari pelaksanaan usaha (Ibrahim, 2003: 32). Analisis kelayakan finansial usaha penangkaran bibit Lampoh Bijeh ini bertujuan untuk menilai sejauh mana manfaat secara finansial yang diterima melalui usaha tersebut dari awal pelaksanaan proyek hingga sekarang, sebagai dasar layak atau tidak usaha dilaksanakan. Banyak perubahan-perubahan yang terjadi di masa mendatang. Kenaikan harga jual atau merosotnya pemasaran yang mempengaruhi penerimaan, kenaikan inflasi yang akan mempengaruhi discount rate, meningkatnya bahan-bahan atau barang-barang tertentu secara relatif yang mempengaruhi biaya, semuanya hendak diperhitungkan lebih dahulu (Soetrisno, 2001: 25). 
Usaha pembibitan tanaman merupakan usaha untuk memenuhi permintaan masyarakat terhadap bibit terutama bibit berlabel. Bibit berlabel adalah bibit yang telah mendapat sertifikat dari Instansi Penyelenggara Sertifikasi atau Balai Pengawasan dan Sertifikasi Benih (BPSB) dan telah teruji kebenarannya. Usaha pembibitan tanaman di Lampoh Bijeh menjadi sentra produksi bibit bagi masyarakat sekitar. Misalnya, tanaman buah-buahan yang dibibitkan yakni mangga, rambutan dan durian. Dalam rangka menunjang pengembangan usaha pembibitan tanaman buah-buahan perlu dilakukan studi kelayakan usaha yang dapat digunakan sebagai informasi dan pengetahuan serta bahan pertimbangan bank dalam membiayai pengembangan usaha pembibitan tanaman buah-buahan.

Analisis usaha pembibitan tanaman perlu dilakukan untuk mengetahui gambaran umum mengenai pendapatan dan pengeluaran/biaya, kemampuan melunasi kredit, serta kelayakan usaha ditinjau dari beberapa kriteria kelayakan finansial. Analisis finansial adalah kegiatan melakukan penilaian dan penentuan satuan rupiah terhadap aspekaspek yang dianggap layak dari keputusan yang dibuat dalam tahapan analisis usaha. Analisis kriteria investasi adalah mengadakan perhitungan mengenai feasible atau tidaknya usaha yang dikembangkan dilihat dari segi investasi. Analisis ini sangat diperlukan apabila usaha yang direncanakan dalam bentuk jenis kegiatan produksi. Faktor-faktor yang perlu diperhatikan adalah perkiraan investasi, modal kerja, biaya operasi dan pemeliharaan, serta perkiraan pendapatan (Ibrahim, 2003: 12).

Kriteria analisis finansial seperti Net Present Value (NPV), Internal Rate of Return (IRR), Pay back Period (PBP) dan Net Benefit/Cost Ratio (Net B/C). Untuk melakukan analisis keuangan tersebut digunakan beberapa asumsi dan parameter keuangan yang didasarkan pada hasil pengamatan di lapangan, masukan dari instansi terkait dan pustaka yang mendukung sehingga akan diperoleh gambaran secara utuh tentang aspek keuangan usaha pembibitan tanaman. Berdasarkan uraian pada latar belakang di atas maka penulis tertarik dan merasa penting untuk melakukan penelitian tentang analisis finansial usaha pembibitan "Lampoh Bijeh" di Kota Langsa.

\section{Identifikasi Masalah}

Apakah usaha pembibitan tanaman Lampoh Bijeh di Kota Langsa layak diusahakan dari segi finansial?.

\section{Tujuan Penelitian}

Untuk mengetahui kelayakan usaha pembibitan tanaman Lampoh Bijeh di Kota Langsa dari segi finansial.

\section{Hipotesis}

Usaha pembibitan "Lampoh Bijeh" di Kota Langsa layak diusahakan dari segi finansial.

\section{METODOLOGI PENELITIAN \\ Lokasi, Objek, Ruang Lingkup dan Waktu penelitian}

Lokasi penelitian yaitu pada usaha pembibitan "Lampoh Bijeh" di Kota Langsa. Pemilihan lokasi ini dengan pertimbangan bahwa usaha tersebut telah melakukan teknik pembibitan dengan baik. Terutama dalam hal memenuhi permintaan bibit tanaman di Kota Langsa. Objek dalam penelitian ini hanya dibatasi pada usaha pembibitan tanaman Lampoh Bijeh di Kota Langsa. Ruang lingkup penelitian ini meliputi analisis biaya dan manfaat pembibitan tanaman Lampoh Bijeh di Kota Langsa.

\section{Metode Pengambilan Sampel dan Pengumpulan Data}

Metode penelitian yang digunakan dalam penelitian ini adalah metode studi kasus (case study). Menurut Susilo Rahardjo (2011: 250) metode studi kasus ini mengungkapkan suatu kebenaran yang menitik beratkan hanya pada satu objek. Objek dalam penelitian ini yaitu usaha pembibitan Lampoh Bijeh di Kota Langsa. Data yang dikumpulkan dalam penelitian ini meliputi data primer dan data sekunder. Data primer dalam penelitian ini diperoleh dengan cara observasi, wawancara dan kuisioner (daftar pertanyaan).

- Observasi, yaitu melakukan pengamatan langsung terhadap objek yang diteliti

- Wawancara yaitu tanya jawab antara peneliti dan informasi yang dilakukan untuk mendapatkan keterangan lebih lengkap dan jelas 
- Kuisioner (daftar pertanyaan), yaitu teknik pengumpulan informasi dengan cara memberikan seperangkat pertanyaan yang telah disusun oleh peneliti.

Data sekunder diperoleh dari instansi terkait yang berhubungan dengan penelitian ini maupun perpustakaan untuk mendapatkan literatur sesuai dengan penelitian ini.

\section{Metode Analisis dan Pengujian Hipotesis}

Data yang diperoleh dari lapangan baik data primer maupun data sekunder diolah dengan mentabulasikan dan kemudian dipindahkan ke dalam bentuk tabelaris sesuai dengan kebutuhan analisis.

\section{Analisis Pendapatan}

1) Pendapatan Kotor

$\mathrm{TR}=(\mathrm{Y}) \mathrm{x}(\mathrm{Py}) \ldots \ldots . \quad($ Ken

Suratiyah, $2006: 65$ )

Keterangan:

TR : Total penerimaan (Total Revenue)

Y : Produk yang diperoleh dalam usahatani

Py : Harga Y (Price)

2) Pendapatan Bersih

$\mathrm{Pd}=\mathrm{TR}-\mathrm{TC} \ldots .$. ( Soekartawi, 2002:58)

Keterangan :

Pd : Pendapatan usahatani

TR : Penerimaan Total (total revenue)

TC : Biaya total (total cost)

\section{Pengujian Hipotesis}

Pengujian hipotesis dalam penelitian ini menggunakan analisis kriteria investasi yaitu:

1. NPV (Net Present Value)

$\mathrm{NPV}=: \sum_{i=1}^{n} N B_{i}(1+i)^{-n}$.(Ibrahim 2003: 144)

Kriteria yang digunakan :

NPV > 0, usaha layak untuk dijalankan

$\mathrm{NPV}=0$, usaha tersebut mengembalikan sama besarnya nilai uang yang ditanamkan

NPV <0, usaha tidak layak untuk dijalankan

2. Net Benefit-Cost Ratio (Net B/C)

Net $\mathrm{B} / \mathrm{C}=\frac{\sum_{i=1}^{n} N B_{i}(+)}{\sum_{i=1}^{n} N B_{i}(-)}$ (Ibrahim, 2003:

151)

Kriteria yang digunakan :

- Net B/C > 1, usaha layak dilakukan
- Net B/C < 1 , usaha tidak layak dilakukan

3. Internal Rate of Return (IRR)

$$
\begin{aligned}
& \text { IRR }=i^{\prime}+\frac{N P V^{+}}{N P V^{+-N P V^{-}}}-i^{\prime \prime}- \\
& i^{\prime}(\text { Ibrahim, 2003: 150) } \\
& \text { Keterangan: } \\
& \text { i' = Tingkat suku bunga yang } \\
& \text { menyebabkan nilai NPV }>0 \\
& \text { i' = Tingkat suku bunga yang } \\
& \text { menyebabkan nilai NPV }<0 \\
& \text { NPV+ = NPV pada i' } \\
& \text { NPV- =NPV pada i" }
\end{aligned}
$$

Kriteria :

IRR $\geq \mathrm{i}$, berarti usaha dapat dilanjutkan

IRR $\leq \mathrm{i}$, berarti usaha lebih baik ditolak atau dihentikan

4. Payback Period

Payback Period merupakan jangka waktu /periode yang diperlukan untuk membayar kembali semua biaya-biaya yang telah dikeluarkan dalam investasi suatu proyek, dengan rumus sebagai berikut:

$$
\begin{aligned}
& P B P=\frac{I}{A b} \text { (Ibrahim, 2003:154) } \\
& \operatorname{dimana}: \\
& \mathrm{I}=\text { besarnya biaya investasi } \\
& \mathrm{Ab}=\text { benefit bersih yg diperoleh }
\end{aligned}
$$

setiap tahunnya

Dengan Indikator:

- Periode pengembalian modal < umur ekonomis, maka usaha layak diusahakan

- Periode pengembalian modal > umur ekonomis, maka usaha layak diusahakan

\section{HASIL PENELITIAN DAN} PEMBAHASAN

\section{Karakteristik Pengusaha Lampoh Bijeh}

Karakteristik pengusaha dalam penelitian ini meliputi umur, pendidikan, pengalaman dalam berusahatani padi sawah dan besar tanggungan keluarga. Rini (2005:26), "pengertian karakteristik individu adalah bagian dari pribadi dan melekat pada diri seseorang. Karakteristik ini mendasari tingkah laku seseorang dalam situasi kerja maupun situasi yang lainnya". Karakteristik akan mempengaruhi pengusaha dalam mengelola usaha selama proses produksi berlangsung. Pengusaha dalam menjalankan usahataninya memiliki fungsi ganda yaitu disamping sebagai manager usaha juga sebagai buruh. 
Hasil penelitian menjelaskan bahwa umur pengusaha adalah 54 tahun, umur tersebut adalah umur yang produktif dalam mengusahakan usaha pembibitan. Tingkat pendidikan adalah 12 tahun, pendidikan pengusaha relatif tinggi. Semakin tinggi tingkat pendidikan pengusaha, maka semakin kreatif pengusaha dalam mengambil berbagai tindakan usaha, begitu juga sebaliknya semakin rendah tingkat pendidikan pengusaha maka semakin lambat dalam mengambil berbagai keputusan strategis usahatani sehingga berpengaruh terhadap keberhasilan usaha. Pengalaman berusaha 10 tahun, pengalaman dalam berusaha pembibitan tanaman sudah cukup lama sehingga kegagalan dan resiko yang akan dihadapi akan semakin kecil dan dapat dikatakan cukup mahir dalam menjalankan usaha pembibitan. Jumlah tanggungan keluarga petani 4 orang, menunjukkan bahwa Jumlah tanggungan keluarga rata-rata 4 orang merupakan tanggungan yang kecil sehingga pengusaha bisa membiayai usaha dengan baik.

\section{Luas Lahan Usaha}

Hasil penelitian menjelaskan bahwa luas tempat usaha pembibitan seluas adalah Tabel V-1. Rata-Rata Penggunaan Tenaga Kerja Usaha Pembibitan Lampoh Bijeh Tahun 2011- 2016

\begin{tabular}{|c|c|c|c|c|}
\hline \multirow[b]{2}{*}{ No } & \multirow[b]{2}{*}{ Tahapan Kerja } & \multicolumn{2}{|c|}{ Tenaga Kerja (HKP) } & \multirow[b]{2}{*}{ Total (HKP) } \\
\hline & & TKDK & TKLK & \\
\hline 1 & Pembuatan Naungan & 37 & 46 & 83 \\
\hline 2 & Pengisian Polibeg & 38 & 47 & 85 \\
\hline 3 & Perbanyakan Tanaman & 20 & 28 & 48 \\
\hline 4 & Penyiraman & 20 & 25 & 45 \\
\hline 5 & Penyiangan & 37 & 42 & 79 \\
\hline 6 & Pemupukan & 19 & 20 & 39 \\
\hline 7 & Pengangkutan & 37 & 46 & 83 \\
\hline 8 & Pemasaran & 20 & 28 & 48 \\
\hline & Total & 228 & 282 & 510 \\
\hline
\end{tabular}

Sumber : Data Primer (diolah), 2016

Tabel V-1 menjelaskan bahwa penggunaan tenaga kerja pada usaha pembibitan tanaman Lampoh Bijeh pada tahun 2011 sampai 2015 sebanyak 510 HKP. Penggunaan tenaga kerja tertinggi pada pengisian polibeg sebanyak 85 HKP dan penggunaan tenaga kerja terendah pada penyiraman sebanyak 45 HKP. Pembuatan naungan memerlukan tenaga kerja yang banyak karena pada bibit tertentu memerlukan naungan sementara yang harus dibongkar pasang. Pekerjaan penyiraman tidak AGRISAMUDRA, Jurnal Penelitian Vol. 4 No.2 Julii - Desember 2017 seluas 16 rante. Luas lahan ini sudah memadai untuk menjalankan usaha pembibitan dengan masing-masing bibit tanaman memerlukan luas lahan yang tidak terlalu luas. Luas lahan yang paling luas biasanya digunakan untuk lahan pembibitan yang paling banyak permintaannya sehingga dibudidayakan dalam jumlah yang banyak sesuai permintaan.

\section{Penggunaan Tenaga Kerja}

Tenaga kerja yang digunakan pada usaha pembibitan tanaman Lampoh Bijeh terdiri dari tenaga kerja dalam keluarga (TKDK) dan luar keluarga (TKLK) yang terdiri dari tenaga kerja pria, wanita dan anakanak. Penggunaan tenaga kerja pada usaha pembibitan Lampoh Bijeh fase kegiatan pengisian polibeg, penyemaian, penanaman bibit, pengokulasian, penyetekan, pemupukan, pemeliharaan dan penjualan/pengangkutan. Dalam menghitung besarnya pencurahan tenaga kerja yang diserap untuk setiap fase kegiatan, seluruhnya dikonversikan ke dalam Hari Kerja Pria (HKP). Rata-rata penggunaan tenaga kerja pada usaha pembibitan Lampoh Bijeh di Kecamatan Langsa Timur dilihat pada tabel V-1 berikut. 
Biaya produksi pada usaha pembibitan

investasi dan biaya operasional. tanaman Lampoh Bijeh terdiri dari biaya

Tabel V-2. Biaya Investasi Pada Usaha Pembibitan Lampoh Bijeh, 2016

\begin{tabular}{|l|l|l|l|l|}
\hline No & \multicolumn{1}{|c|}{ Uraian } & $\begin{array}{c}\text { Jumlah } \\
\text { (Unit) }\end{array}$ & \multicolumn{1}{|c|}{$\begin{array}{c}\text { Harga Satuan } \\
(\mathrm{Rp} / \text { Unit })\end{array}$} & \multicolumn{1}{|c|}{$\begin{array}{c}\text { Total Harga } \\
(\mathrm{Rp})\end{array}$} \\
\hline 1 & Bangunan & 1 & 120.000 .000 & 120.000 .000 \\
2 & Naungan & 1 & 10.560 .000 & 10.560 .000 \\
3 & Kebun Induk & 1 & 50.000 .000 & 50.000 .000 \\
4 & Sumur & 1 & 2.000 .000 & 2.000 .000 \\
5 & Pagar & 1 & 11.225 .000 & 11.225 .000 \\
6 & Pompa Air & 1 & 5.000 .000 & 5.000 .000 \\
7 & Handsprayer & 2 & 500.000 & 1.000 .000 \\
\hline Total & \multicolumn{5}{|l}{} \\
\hline
\end{tabular}

Sumber : Data Primer (diolah), 2016

Tabel V-2 menjelaskan bahwa total biaya investasi usaha pembibitan tanaman Lampoh Bijeh sebesar Rp. 1997.785.000,-. Biaya investasi terbesar pada investasi bangunan dengan nilai Rp. 120.000.000,- sedangkan biaya investasi terendah pada investasi pada handsprayer sebesar Rp.1.000.000,-.

Biaya operasional adalah seluruh biaya untuk menjalankan operasional usaha pembibitan yang jumlahnya bisa berubah seiring dengan jumlah bibit yang akan diproduksi. Jumlah bibit perjenis tanaman juga mengalami perubahan pada setiap tahun sejalan dengan jumlah permintaan dari konsumen serta kontrak yang disepakati antara pihak pengusaha pembibitan dan konsumen. Biaya operasional pada usaha pembibitan tanaman Lampoh Bijeh pada tahun 2011 sampai 2015 yaitu sebesar Rp. 273.521.166,70,- sedangkan biaya operasional terbesar yaitu pada biaya penyusutan sebesar 116.897.916,7,- dan biaya operasional terkecil adalah pada biaya pembelian biji jambu jamaika, jeruk purut, belimbing dan asam

\section{Produksi Bibit}

Produksi bibit pada usaha pembibitan tanaman Lampoh Bijeh tertinggi terdapat pada bibit tanaman kelapa sawit sebanyak 6.825 batang bibit, sedangkan produksi bibit terkecil terdapat pada jenis bibit tanaman asam jawa yaitu 971 batang bibit. Tingginya produksi bibit kelapa sawit karena permintaan akan bibit ini tinggi yang disebabkan petani kelapa sawit melalukan kegiatan perluasan areal kebun dan menanam kembali tanaman kelapa sawit tua dengan tanaman kelapa sawit baru. Bahkan adanya konversi dari tanaman karet ke tanaman kelapa sawit yang mana harga kelapa sawit lebih stabil dibandingkan dengan harga karet.

\section{Nilai Produksi (Penerimaan Kotor) Usaha \\ Nilai produksi usaha pembibitan tanaman Lampoh Bijeh dari tahun 2011 sampai 2015 dapat dilihat pada tabel V-5 berikut ini.} gelugur.

Tabel V-5. Produksi Pada Usaha Pembibitan Tanaman Lampoh Bijeh Tahun 2011-2015

\begin{tabular}{|c|c|c|}
\hline No & Tahun & Total Penerimaan (Rp) \\
\hline 1 & 2011 & 97.402 .600 \\
\hline 2 & 2012 & 124.250 .200 \\
\hline 3 & 2013 & 140.230 .000 \\
\hline 4 & 2014 & 164.075 .000 \\
\hline 5 & 2015 & 186.170 .000 \\
\hline & Jumlah & 712.127 .800 \\
\hline
\end{tabular}

Sumber : Data Primer (diolah), 2016 
Tabel V-5 menjelaskan bahwa total penerimaan usaha pembibitan tanaman Lampoh Bijeh tahun 2011 sampai 2015 sebesar Rp. 712.127.800,-. Penerimaan terbesar pada tahun 2015 yaitu sebesar Rp. 186.170.000,-, sedangkan penerimaan terkecil pada tahun 2011 yaitu sebesar Rp. 97.402.600,-. Terjadi peningkatan penerimaan dari tahun ke tahun usaha pembibitan tanaman Lampoh Bijeh sehingga dapat disimpulkan adanya peningkatan kegiatan usaha.

Tabel V-6. Rata-Rata Pendapatan Bersih usaha pembibitan tanaman Lampoh Bijeh2011-2015

\begin{tabular}{|l|l|l|l|l|}
\hline No & Tahun & $\begin{array}{l}\text { Penerimaan } \\
(\text { Rp/Tahun })\end{array}$ & $\begin{array}{l}\text { Biaya Operasional } \\
(\text { Rp/Tahun })\end{array}$ & $\begin{array}{l}\text { Pendapatan } \\
\text { (Rp/Tahun) }\end{array}$ \\
\hline 1 & 2011 & 97.402 .600 & 27.937 .350 & 69.465 .250 \\
2 & 2012 & 124.250 .200 & 25.932 .150 & 98.318 .050 \\
3 & 2013 & 140.230 .000 & 32.049 .375 & 108.180 .625 \\
4 & 2014 & 164.075 .000 & 31.873 .125 & 132.201 .875 \\
5 & 2015 & 186.170 .000 & 38.831 .250 & 147.338 .750 \\
\hline \multicolumn{4}{|l}{ Jumlah } & 555.504 .550 \\
\hline
\end{tabular}

Sumber : Data Primer (diolah), 2016

Tabel V-6 menjelaskan bahwa total pendapatan bersih pada usaha pembibitan tanaman Lampoh Bijeh tahun 2011-2015 sebesar Rp. 555.504.550,-. Pendapatan bersih terbesar diperoleh pada tahun 2015 yaitu sebesar Rp. 147.338.750,-, sedangkan pendapatan bersih terkecil diperoleh pada tahun 2011 yaitu sebesar Rp. 69.465.250,-.

\section{Pendapatan Bersih Usaha}

Pendapatan bersih sangat dipengaruhi oleh besarnya nilai produksi dan besarnya biaya produksi usaha pembibitan tanaman Lampoh Bijeh. Pendapatan bersih yaitu selisih antara nilai produksi dengan total biaya produksi. Pendapatan bersih usaha pembibitan tanaman Lampoh Bijeh tahun 2011-2015 dapat dilihat pada tabel V-6 berikut ini.

\section{Analisis Finansial Usaha Pembibitan Tanaman Lampoh Bijeh}

Untuk menganalisis apa usaha pembibitan tanaman Lampoh Bijeh layak atau tidak untuk dikerjakan maka dilakukan analisis finansial dengan 4 (empat) kriteria penilaian investasi yaitu: NPV, Net B/C, IRR dan PBP. Hasil analisis finansial usaha pembibitan tanaman Lampoh Bijeh dapat dilihat pada tabel V-7 berikut.

Tabel V.7. Hasil Analisis Finansial

\begin{tabular}{|l|l|r|c|c|}
\hline No & $\begin{array}{l}\text { Kriteria } \\
\text { Investasi }\end{array}$ & Hasil Analisis & $\begin{array}{l}\text { Kriteria } \\
\text { Penerimaan }\end{array}$ & Kesimpulan \\
\hline 1 & NPV & Rp. 46.843.766,53 & $>0$ & Layak \\
2 & IRR & $12,4 \%$ & $>12 \%$ & Layak \\
3 & Net B/C & 1,77 & $>1$ & Layak \\
4 & PBP & 3,42 Tahun & $<5$ Tahun & Layak \\
\hline
\end{tabular}

Sumber : Data Primer (diolah), 2016

Tabel V-7 menjelaskan bahwa hasil analisis finansial untuk 4 (empat) penilaian kriteria investasi semuanya layak. Nilai NPV sebesar Rp. 46.843.766,53 adalah lebih besar dari 0 maka dari sisi NPV usaha pembibitan tanaman Lampoh Bijeh layak untuk dikerjakan. Nilai IRR sebesar $12,4 \%$ lebih besar dari bunga pinjaman bank berlaku yaitu $12 \%$, maka dari sisi IRR usaha pembibitan tanaman Lampoh Bijeh layak untuk dikerjakan. Nilai Net B/C sebesar 1,77 adalah lebih besar dari 1, maka dari sisi Net B/C usaha pembibitan tanaman Lampoh Bijeh layak untuk dikerjakan. Nilai AGRISAMUDRA, Jurnal Penelitian Vol. 4 No.2 Julii-Desember 2017
PBP sebesar 3,42 tahun adalah lebih kecil dari umur proyek yaitu 5 tahun, maka dari sisi PBP usaha pembibitan tanaman Lampoh Bijeh layak untuk dikerjakan.

\section{KESIMPULAN DAN SARAN \\ Kesimpulan}

Hasil analisis finansial usaha pembibitan Lampoh Bijeh Kota Langsa untuk 4 (empat) penilaian kriteria investasi diperoleh kesimpulan sebagai berikut:

1. Nilai NPV sebesar Rp. 46.843.766,53 adalah lebih besar dari 0 maka dari sisi 
NPV usaha pembibitan tanaman Lampoh Bijeh layak untuk dikerjakan.

2. Nilai IRR sebesar $12,4 \%$ lebih besar dari bunga pinjaman bank berlaku yaitu $12 \%$, maka dari sisi IRR usaha pembibitan tanaman Lampoh Bijeh layak untuk dikerjakan.

3. Nilai Net B/C sebesar 1,77 adalah lebih besar dari 1, maka dari sisi Net B/C usaha pembibitan tanaman Lampoh Bijeh layak untuk dikerjakan.

4. Nilai periode pengembalian modal (PBP) sebesar 3,42 tahun adalah lebih kecil dari umur proyek yaitu 5 tahun, maka dari sisi PBP usaha pembibitan tanaman Lampoh Bijeh layak untuk dikerjakan.

\section{Saran-saran}

1. Diharapkan kepada pengusaha usaha pembibitan tanaman Lampoh Bijeh dapat memperluas pemasaran bibit tanaman yang diproduksi, agar pendapatan dapat meningkat dimasa yang akan datang.

2. Perlu adanya perhatian pemerintah agar memberikan akses pasar, modal dan pengembangan usaha pembibitan tanaman Lampoh Bijeh menjadi lebih besar, agar menjadi pensuplay bibit bagi Propinsi Aceh pada umumnya.

\section{DAFTAR PUSTAKA}

Hadisapoetra. 2000. Biaya dan Pendapatan di Dalam Usahatani. UGM: Yogyakarta

Hair, Lamb, Mc. Daniel, 2001. Manajemen Pemasaran, Jilid Satu dan Dua. Alih Bahasa Oleh David Octarevia, Salemba Empat Jakarta.

Hernanto, F., 2004. Ilmu Usahatani. Penebar Swadaya, Jakarta.

Husein Umar, 2003. Metode Riset Bisnis, Jakarta: PT Gramedia Pustaka Utama

Husein Umar, 2007. Metode Studi Kelayakan Bisnis, Jakarta: PT Gramedia Pustaka Utama

Ibrahim, Yakob. 2010. Studi Kelayakan Bisnis. Bineka Cipta. Jakarta.
Kadariah, 2001. Evaluasi Proyek : Analisis Ekonomis. Lembaga Penerbitan Fakultas Ekonomi Universitas Indonesia. Jakarta

Mubyarto, 2002. Pengantar Ekonomi Pertanian. LP3ES. Jakarta.

Nusmawarhaeni, 2001. Mengenal Buah Unggul Indonesia. Cetakan IX. Penebar Swadaya. Jakarta

Rangkuti, 2012. Teknik Membedah Kasus Bisnis. Salemba Empat. Jakarta

Setiawan, A.I, 1999. Kiat Memilih Bibit Tanaman Buah. Penebar Swadaya. Jakarta

Siregar, Tumpal. H.S, 2008. Budidaya Tanaman Cokelat. Penebar Swadaya, Jakarta

Soekartawi, 2002. Ilmu Usahatani dan Penelitian Untuk Pengembangan Petani Kecil, Penerbit Universitas Indonesia, Jakarta

Suratiyah, Ken. 2006. Ilmu Usahatani. Cetakan I. Jakarta: Penerbit Penebar Swadaya

Tohar. (2000). Membuka Usaha Kecil. Yogyakarta : Kanisius

Widodo,S. 2008. Partisipasi, Pemberdayaan dan Pembangunan. http://learning.slametwidodo.com

Winarno, F.G . 1990. Pertanian Untuk Pangan. Gramedia Pustaka Utama, Jakarta 